\title{
Antioxidant defense capacity of ovarian tissue after vitrification in a metal closed system
}

\author{
Eloísa T. Massignam ${ }^{1}$, Maitê Ferreiraㄹ ${ }^{2}$, Eduardo Sanguinet ${ }^{2}$, Ágata Dupont ${ }^{2}$, Fábio Klamt ${ }^{1}$, Nilo Frantz ${ }^{3}$, Adriana \\ Bos-Mikich² \\ ${ }^{1}$ Department of Biochemistry, ICBS, Federal University of Rio Grande do Sul, Porto Alegre, RS, Brazil \\ ${ }^{2}$ Department of Morphological Sciences, ICBS, Federal University of Rio Grande do Sul, Porto Alegre, RS, Brazil \\ ${ }^{3}$ Nilo Frantz Human Fertility Center, Porto Alegre, RS, Brazil
}

\begin{abstract}
Objective: The present study analyzed the quality of bovine ovarian tissue after vitrification in a metal closed chamber, in terms of putative changes in tissue viability (lactate dehydrogenase -LDH- release), anti-oxidant defenses, and redox parameters caused by cryopreservation.

Methods: Small and large fragmented bovine ovarian tissue specimens were vitrified in a metal chamber. After rewarming, tissue samples were fixed or cultured for 48 hours. Glutathione (GSH), protein sulfhydryl content, Total Radical Trapping Antioxidant Potential (TRAP), and lactate dehydrogenase were analyzed immediately after rewarming and after tissue culture.

Results: No changes in antioxidant parameters or viability of rewarmed tissue samples were found immediately or $48 \mathrm{~h}$ after vitrification. The method of vitrification in a metal closed chamber used in this study preserved the quality of bovine ovarian tissue. Furthermore, our data showed that the size of the tissue specimens did not affect post-vitrification biochemical viability parameters.

Conclusions: We believe that the vitrification methodology employed in the present study is safe and effective,
\end{abstract} and should be evaluated for use in humans.

Keywords: Ovarian tissue, vitrification, oxidative stress

\section{INTRODUCTION}

Ovarian tissue cryopreservation is an option for the restoration of hormonal and reproductive function of females facing cancer. Presently, ovarian tissue cryopreservation is primarily performed using slow freezing protocols. However, comparative studies have demonstrated that vitrification might more effectively preserve ovarian structure and function (Tokieda et al., 2002; Keros et al., 2009). Most vitrification procedures employ an open system to directly expose the biological material to liquid nitrogen (Sugimoto et al., 2000; Tokieda et al., 2002; Migishima et al., 2003; Almodin et al. 2004; Chen et al., 2006; Keros et al., 2009; Isachenko et al., 2009; Sheikhi et al., 2011; Fabbri et al., 2010). Considering that the consequences of cryostorage can only be confirmed over long periods of time, and since it is impossible to guarantee there will never be any cross-contamination, current recommendations support the use of systems in which there is no direct contact between the cryopreserved material and liquid nitrogen (Pomeroy et al., 2010). Our group has developed a metal chamber in which ovarian tissue specimens are vitrified without direct contact with liquid nitrogen (Aquino et al., 2014). Histological analysis of rewarmed tissue specimens showed well-preserved stroma, primordial, and primary follicles (Marques et al., 2015; Aquino et al., 2014).
However, ex-vivo tissue manipulation and cryopreservation may induce oxidative stress, thus damaging cells and compromising tissue viability and function after re-transplantation. Reactive oxygen species (ROS) are unstable molecules produced during normal cell physiological processes. These molecules play important roles in cell signaling, including processes involved in reproduction (de Lamirande \& Gagnon, 1995; Shkolnik et al., 2011; Vu et al., 2012; Silva et al., 2015). However, ROS have also been associated with adverse effects on reproduction, particularly on gametes, including impaired embryonic development and diseases in the offspring (Ruder et al., 2008; Xiao et al., 2012).

Under normal physiological conditions, cells and tissues produce and store antioxidant agents, especially glutathione (GSH) and protein sulfhydryl groups, to counteract oxidant effects and defend cells from ROS. Imbalances between ROS production and defense mechanisms protecting cells against damaging oxidative molecules result in oxidative stress. Tissue and cell manipulation may lead to excessive ROS production, which may in turn lead to cell and tissue damage and eventually death.

There is no information on whether the vitrification process compromises the antioxidant defense capacity provided by the intracellular defense mechanisms of oocytes, follicular cells, and stroma of the ovarian tissue. Although thawed graft performance after transplantation is the ultimate validation of any ovarian tissue cryopreservation method, biomarkers are needed to predict tissue viability after cryopreservation.

The aim of this study was to assess the viability of bovine ovarian tissue specimens using a metal closed system for vitrification by measuring the tissue levels of GSH and protein sulfhydryl groups, total radical trapping anti-oxidant potential, and lactate dehydrogenase production in cryopreserved specimens immediately after rewarming and after culture.

\section{MATERIALS AND METHODS}

\section{Tissue manipulation and vitrification}

Bovine ovaries were collected at a local abattoir and transported to the laboratory within two hours of slaughter in a sterile glass vessel containing saline solution at room temperature $\left(\mathrm{RT} ; \sim 23^{\circ} \mathrm{C}\right)$. Cortex slices were cut in two sizes: $1 \times 1 \times 3 \mathrm{~mm}$ (small fragments " $\mathrm{S}$ ") and $1 \times 1 \times 5 \mathrm{~mm}$ (large fragments "L") with a scalpel. The specimens were transferred first to equilibrium solution (ES) with $7.5 \%$ ethylene glycol (EG) and DMSO and then to vitrification solution (VS) with 15\% EG and DMSO, both in HTF (Irvine) medium for 25 and $15 \mathrm{~min}$, respectively. The fragments were gently transferred from one solution to the next with the help of fine sterile paintbrushes to avoid tissue damage and to carry the least amount of medium in each transfer. 
Ten to 12 tissue specimens from different ovaries were placed in the bottom of a metal cryovial (Patent no.: BR 202013019739 0); a lid was tightly fastened on the top of the vial and the system was immersed in liquid nitrogen (LN2) for storage from one week to two months (Aquino et al., 2014). For each experimental replicate, four to five fresh samples from different ovaries were transferred directly to lysis buffer $(0,25 \mathrm{M}$ sucrose, $1 \mathrm{mM}$ EDTA, $10 \mathrm{mM}$ Tris- $\mathrm{HCl}(\mathrm{pH} 7.5), 20 \%$ glycerol, $0.1 \%$ phenylmethylsulfonyl) to be used as fresh controls for biochemistry assays and then stored at $-80^{\circ} \mathrm{C}$. The Institutional Ethics Committee of the Federal University of Rio Grande do Sul approved the study (permit no. 25088).

\section{Tissue rewarming and culture}

The cryovials were pulled out of liquid nitrogen and exposed to tap water for $30 \mathrm{sec}$ to allow the lids to be unfastened. Then, the bottoms of the cryovials were immersed in water at $370 \mathrm{C}$ for $1 \mathrm{~min}$. The rewarmed contents were gently removed from the bottom of the capsule and transferred to the firstwarming solution containing $1 \mathrm{M}$ sucrose for $1 \mathrm{~min}$, followed by the second solution containing $0.5 \mathrm{M}$ sucrose for $3 \mathrm{~min}$, and the last solution containing $0.25 \mathrm{M}$ sucrose for five minutes. All solutions were at room temperature. After rewarming, the fragments were transferred to lysis buffer and stored at $-80^{\circ} \mathrm{C}$ or cultured for 48 hours in $\mathrm{HTF}$ medium at $38.5^{\circ} \mathrm{C}$. Fresh tissue samples from different ovaries were placed under the same culture conditions. After culture, the specimens were transferred to lysis buffer and stored at $-80^{\circ} \mathrm{C}$ for further analysis. The culture media were transferred to Eppendorf tubes containing $500 \mu \mathrm{L}$ of lysis buffer and stored at $-80^{\circ} \mathrm{C}$ for LDH assay.

Three experimental replicates were carried out.

GSH, Total Radical-Trapping Antioxidant Potential (TRAP), Reduced Thiol (-SH) and LDH Levels Reagents and Equipment

All reagents were obtained from Sigma-Aldrich Brazil (São Paulo, Brazil), except when otherwise indicated. Spectrophotometric measurements were assayed in a 96well microplate reader (SpectraMax i3, Molecular Devices).

\section{Tissue preparation}

The ovarian tissue fragments were transferred to a 25 $\mathrm{mL}$ glass Potter-Elvehjem Homogenizer containing $500 \mu \mathrm{L}$ of lysis buffer. The tissue specimens were struck several times with a pestle until a homogenate was obtained. The homogenate was centrifuged at 500rpm for 5 minutes and the supernatant was collected for protein, GSH, sulfhydryl, and TRAP testing.

\section{Total Protein Content Quantification}

Bradford assays were performed to measure the protein levels of each experimental group and repeats (Zor \& Selinger, 1996). All samples were diluted with lysis solution.

These values were used to correct GSH, sulfhydryl, and TRAP test results.

\section{Reduced Glutathione Concentration Assay}

GSH concentrations were measured according to Browne \& Armstrong (1998) with minor modifications. In summary, the samples $(1 \mu \mathrm{g}$ protein $/ \mu \mathrm{L})$ were first deproteinized with meta-phosphoric acid, centrifuged at $7000 \mathrm{~g}$ for $10 \mathrm{~min}$, and immediately used for GSH quantification. $185 \mu \mathrm{L}$ of $100 \mathrm{mM}$ sodium phosphate buffer ( $\mathrm{pH} 8.0)$ containing $5 \mathrm{mM}$ ethylenediaminetetraacetic acid and $15 \mu \mathrm{L}$ of o-phthaldialdehyde $(1 \mathrm{mg} / \mathrm{mL})$ were added to $30 \mu \mathrm{L}$ of previously deproteinized supernatant. The mixture was incubated at room temperature in a dark room for $15 \mathrm{~min}$.
Fluorescence was measured using excitation and emission wavelengths of 350 and $420 \mathrm{~nm}$, respectively. The final quantity of glutathione was calculated using a GSH standard curve (Browne \& Armstrong, 1998). Values were corrected for the protein levels determined by the Bradford assay.

\section{Reduced Thiol (-SH) Levels Assay}

Sulfhydryl group ( $-\mathrm{SH}$ ) levels were determined by measuring absorbance of DTNB at $412 \mathrm{~nm}$. DTNB $10 \mathrm{mM}$ (5,5'-dithionitrobis 2-nitrobenzoic acid) was added to the samples and sulfhydryl levels were determined by reacting samples with 5-thio-2-nitrobenzoic acid (Nbs). Results were expressed in nanomoles of sulfhydryl per $\mu \mathrm{g}$ of protein (Ellman, 1959).

\section{Total Radical-Trapping Antioxidant Potential (TRAP) Assay}

Non-enzymatic total antioxidant capacity was assessed through the Total Radical-Trapping Antioxidant Potential (TRAP) assay (Lissi et al., 1995). This assay is based on oxidized luminol-chemiluminescence measurement induced by AAPH (2,2'-Azobis 2-amidinopropane) decomposition in glycine buffer ( $\mathrm{pH}$ 8.6). After system (buffer + luminol $+\mathrm{AAPH}$ ) stabilization ( $2 \mathrm{~h}$ at room temperature protected from direct light), samples were added and chemiluminescence was monitored using a Wallace $1450 \mathrm{Mi}-$ croBeta TriLux Liquid Scintillation Counter \& Luminometer (Perkin Elmer). A chemiluminescence time curve was obtained and the relative 1 -area under curve (1-AUC) was used for analysis (Dresch et al., 2009).

\section{LDH assay}

Lactate dehydrogenase (LDH) released by necrotic cells may be used as a marker of cell viability (Korzeniewski \& Callewaert, 1983).

The release of $\mathrm{LDH}$ from cultured cells into the medium was quantified with a colorimetric cytotoxicity detection kit (Roche, Mannheim, Germany), used according to manufacturer instructions. In summary, culture media were collected at $48 \mathrm{~h}$ of culture. The samples were stored at $-20^{\circ} \mathrm{C}$ and measurements were performed based on the protocol provided by the manufacturer.

\section{Statistical Analysis}

The results were expressed as the mean values \pm SD calculated from three independent experiments. Except for the TRAP assays, where the non-parametric Kruskal-Wallis test was used, data were analyzed by one-way analysis of variance (ANOVA). Differences with $p<0.05$ were considered statistically significant.

\section{RESULTS}

The analysis of the antioxidant parameters of cryopreserved ovarian tissue specimens showed that the present vitrification protocol using DMSO and EG as cryoprotectants and the metal capsule did not impair tissue antioxidant defense capacity after rewarming and after 48 $h$ in culture. No significant tissue death was observed after $48 \mathrm{~h}$, as measured by the LDH assay. In addition, the study revealed that the size of the tissue fragments did not significantly affect antioxidant defenses or viability in terms of tissue or cell death.

\section{GSH assay}

The GSH levels of fresh controls (FC), vitrified specimens without culture, vitrified cultured specimens, and fresh cultured specimens of ovarian tissue are presented in Figure 1. Statistical analysis showed that there was no significant difference between fresh, vitrified and/or cultured 
ovarian tissue specimens for GSH content $(P=0.750)$. Fresh controls presented the highest GSH levels. Fragment size did not affect GSH levels among groups. However, a more detailed examination showed that $S$ fresh samples maintained the same GSH level after 48 hours of culture. In the vitrified groups, $S$ and $L$ fragments had non-significant declines in GSH levels during culture when compared to the levels observed before culture (Figure 1).

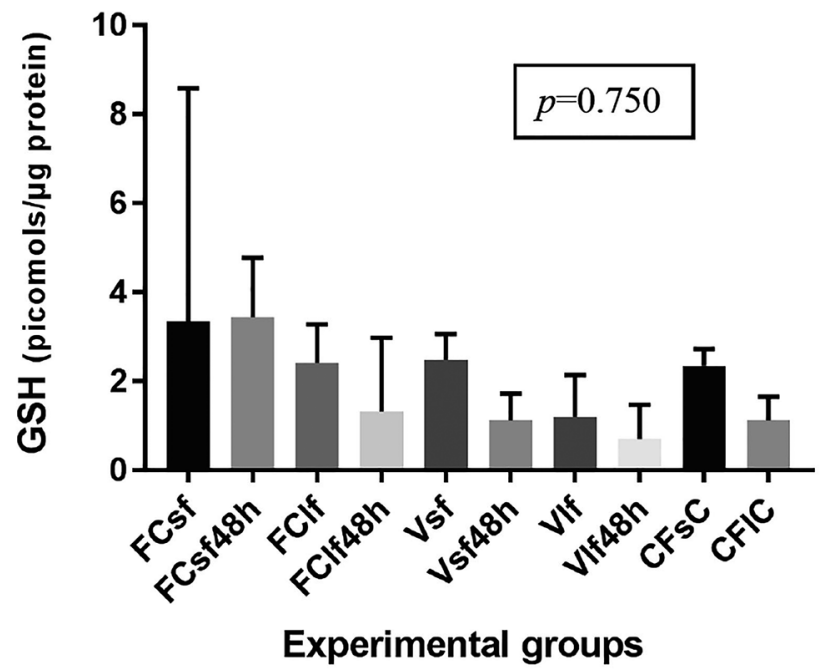

Figure 1. GSH values in fresh and vitrified/rewarmed ovarian tissue specimens. FCsf: Fresh control, small fragments; FCsf 48h: Fresh control, small fragments, 48 hours of culture; FClf: Fresh control, large fragments; FClf48h: Fresh control, large fragments, 48 hours of culture; Vsf: Vitrified small fragments; Vsf48h: Vitrified small fragments, 48 hours of culture; VIf: Vitrified large fragments; VIf48h: Vitrified large fragments, hours of culture; CfsC: Culture fresh, small control; CflC: Culture fresh, large control.

\section{Protein sulfhydryl assay}

Thiol-based antioxidant levels are shown in Figure 2. The results showed no significant difference between experimental groups, regardless of fragment size $(p=0.915)$. However, it is interesting to observe that protein sulfhydryl levels declined when $S$ and $L$ fresh samples were cultured for 48 hours. Conversely, rewarmed samples showed higher protein sulfhydryl levels and values closer to the ones seen in fresh controls, after 48 hours of culture (Figure 2 ).

\section{TRAP assay}

Figure 3 shows TRAP levels for all experimental groups and controls. In the two culture control groups, small and large fragments were not included in the analysis because there were only two repeats instead of three. There were no significant differences in TRAP levels $(p=0.060)$ in $S, L$, vitrified, vitrified and cultured, and non-vitrified controls (Figure 3).

\footnotetext{
Detection of LDH production in cultured ovarian tissue specimens

Cell viability (Preissler et al., 2016) was inferred from lactate dehydrogenase levels in culture media where vitrified/rewarmed, $\mathrm{S}$ and $\mathrm{L}$ fragments, and fresh samples were cultured for 48 hours. Results showed that LDH release did not differ significantly between cryopreserved and fresh, $\mathrm{S}$ and $\mathrm{L}$ fragments after 48 hours of culture $(p=0.371)$ (Figure 4).
}

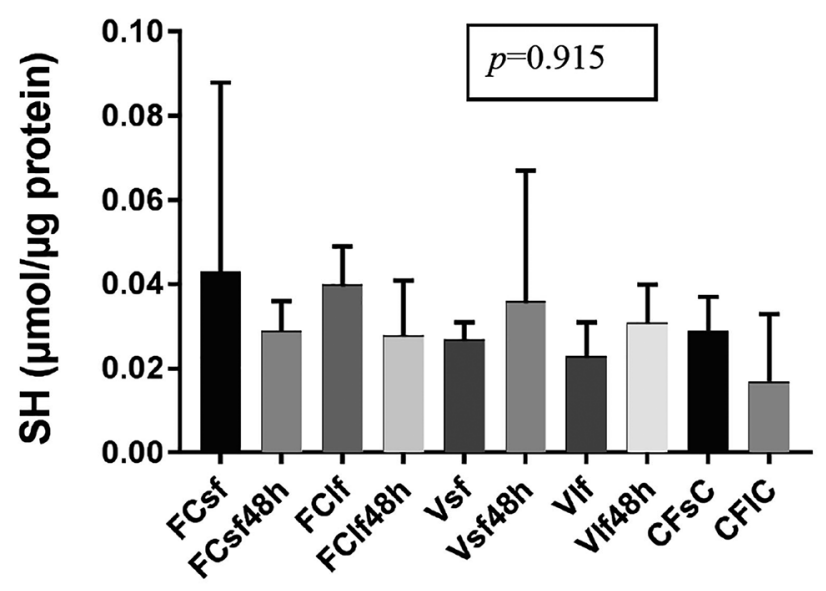

Experimental groups

Figure 2. Protein sulfhydryl levels in fresh and vitrified/ rewarmed ovarian tissue specimens. See Figure 1 for definitions of the control, vitrification, and culture groups.

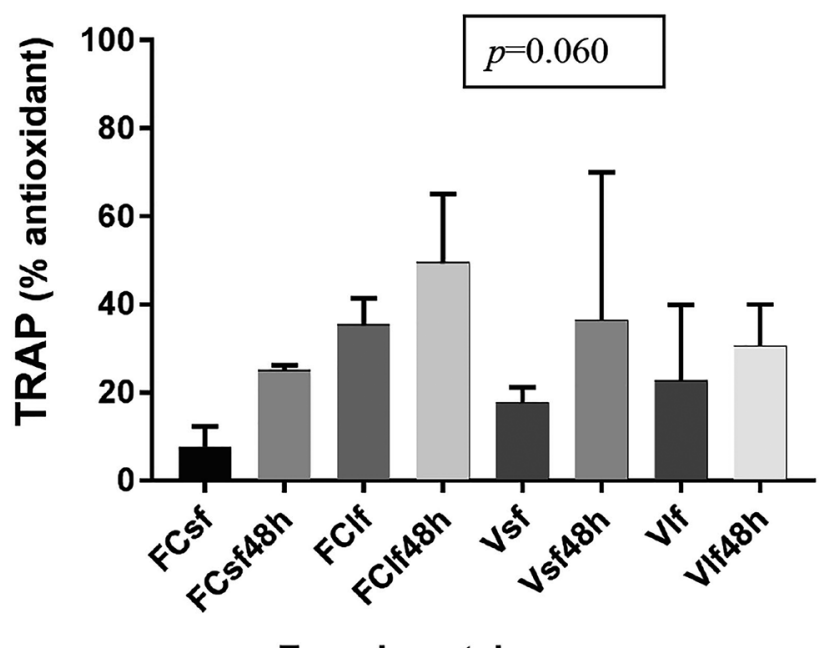

\section{Experimental groups}

Figure 3. TRAP values in fresh and vitrified/rewarmed ovarian tissue specimens. See Figure 1 for definitions of the control, vitrification, and culture groups.

\section{DISCUSSION}

Our results demonstrated that the protocol described in this report using a closed metal chamber for bovine ovarian tissue vitrification did not significantly alter the redox status of cryopreserved specimens. In addition, fragment size did not significantly affect post-rewarming tissue antioxidant capacity or cell death. The data showed that there was no significant alteration in GSH or sulfhydryl levels, TRAP capacity or LDH production, in $S$ and $L$ vitrified/rewarmed tissue specimens when compared to fresh controls immediately after rewarming and after 48 hours of culture.

Despite the abundant literature on the vitrification of isolated ovarian follicles and tissues from different species using different protocols, reported results vary in terms of cell and tissue viability or live births. More importantly, most vitrification methods use open systems to expose gametes, embryos, and tissue specimens to liquid nitrogen. This is a critical point to be taken into consideration, particularly when human tissue samples are considered. Previous reports showed that liquid nitrogen might induce microbial contamination of biological specimens (Bielanski 


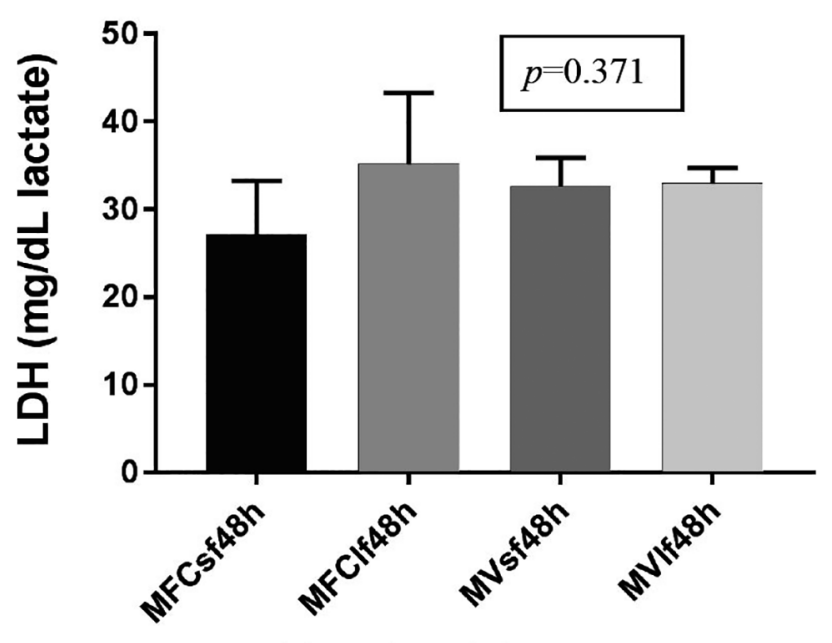

Experimental groups

Figure 4. LDH measurements values in fresh and vitrified/rewarmed ovarian tissue specimens after 48 hours of culture. MFCsf48h: Medium from fresh control of small fresh fragment, cultured for 48 hours; MFClf48h: Medium from fresh control of large fresh fragment, cultured for 48 hours; MVsf48h: Medium from Vitrified small fragment, cultured for 48 hours; MVIf48h: Medium Vitrified large fragment, cultured for 48 hours.

et al., 2000). Thus, a safe and efficient method to vitrify human ovarian samples is urgently needed. Our group has developed a metal chamber in which bovine and zebrafish ovarian tissues were vitrified without any direct contact with LN2. Histological analysis of the rewarmed samples showed well-preserved primordial and primary follicles, in addition to stroma cells and collagen fibers (Aquino et al., 2014; Marques et al., 2015).

In order to perform a physiological assessment of rewarmed ovarian tissue, the biochemical protocols typically used for fluids and cell suspensions were adjusted to process bovine ovarian tissue and assess antioxidant capacity and cell death after cryopreservation and culture. The use of the bovine model is justified by the fact that it has a similar cellular and extracellular matrix composition and anatomical organization to the human ovary.

The generation of free reactive oxygen species is a normal physiological process in living cells. However, when ROS production exceeds cell defense capacity, cell DNA may be damaged. Cell damage due to free oxygen radicals produced during cryopreservation procedures is known to affect cell quality. In 1997, Mazur put forward the hypothesis that Oxyrase, an Escherichia coli membrane preparation (Adler, 1990) that reduces oxygen levels in freezing solutions, might protect cells by reducing the production of superoxide free radicals and other reactive oxygen species during the cryopreservation of mammalian sperm (Mazur et al., 2000). Thus, vitrification protocols in which there is exposure to relatively high levels of cryoprotectants, as in freezing procedures, may induce an excessive generation of ROS in cells and tissues and cause cell damage and impairment or total loss of viability after rewarming. GSH measurements made in this study showed that there was no statistically significant difference in the GSH levels of fresh and cryopreserved specimens. However, there was a perceptible, albeit non-significant, decline in the GSH levels of vitrified versus fresh samples during culture. This difference in GSH concentration between fresh and cryopreserved specimens during culture may account for the amount of GSH that was oxidized as a result of the vitrification process.

Vitrified specimens had a non-significant increase in protein sulfhydryl content during culture. A possible explanation is that vitrification/rewarming media and processes are stressing to the fragments, which prompts the oxidation of sulfhydryl groups. Culture medium is supposed to be a stable and ideal environment for cell survival; therefore, sulfhydryl groups are not oxidized and vital cell processes are preserved.

TRAP assay results were not statistically different among groups; all groups, fresh and cryopreserved, had high TRAP values after 48 hours of culture. As mentioned above, a possible explanation is that culture conditions are cell-friendly and cells do not use their non-enzymatic antioxidant defenses as much compared to when they undergo vitrification or tissues are manipulated prior to cryopreservation or culture.

$\mathrm{LDH}$ is a soluble cytoplasmic enzyme present in almost all cells that is released into the extracellular space when the plasma membrane is damaged (Burd \& Usategui-Gomez, 1973). Thus, LDH assays may be used to determine the amount of cell death under a given condition (Smith et al., 2011). The linearity of the assay allows it to be used to enumerate the proportion of necrotic cells in a sample (Chan et al., 2013). Cell death by necrosis is usually triggered by external factors such as toxic chemicals. The high concentrations of cryoprotectants used in vitrification might produce irreversible toxic effects on cells and tissues when the procedure is not accurately performed. Considering that the vitrification protocol used in the present study does not induce irreversible cell damage, necrosis was not expected. Our data on LDH concentrations during culture of fresh and vitrified/rewarmed tissue samples showed that there was no increase in cell death due to vitrification. Furthermore, the data indicated that the obtained LDH values ( 25 to $34 \mathrm{mg} / \mathrm{dL}$ ) were within the physiological range expected for human plasma and cerebrospinal fluid.

Studies have shown that the vitrification of immature mouse whole ovaries produced no harmful effects on the subsequent development of isolated follicles (Haidari et al., 2008; Mazoochi et al., 2009). Other authors have demonstrated that the increase in ROS levels observed after the vitrification of mouse ovary specimens was reversed during culture after rewarming (Abedelahi et al., 2010; Hatami et al., 2014). Although ours was not a murine model, our findings corroborated the results published in the cited studies and showed that ovarian tissue vitrification produced no harmful effects on subsequent tissue viability in terms of antioxidant defense capacity and cell death.

The purpose of cryopreserving ovarian tissue is not limited to fertility preservation. Ovarian tissue cryopreservation has the potential to restore endocrine and reproductive ovarian function, a possible benefit for women not immediately interested in reproduction, but who want to have their ovarian physiology restored. Thus, despite the importance of the findings described by Abedelahi et al. (2010) and Hatami et al. (2014), follicle isolation and in vitro maturation might not be the better options to treat prepubertal girls or young women who do not want to depend on hormone replacement therapy to secure their female hormone profile. In addition, follicle isolation is not as easily performed in human ovaries as it is in mice, because of the larger amount of fibrous extracellular matrix in humans. Therefore, tissue fragment cryopreservation seems to be a more generally acceptable procedure for fertility preservation. Safe protocols are required to ensure the feasibility of the procedure.

The overall results reported in this paper showed that tissue specimen size was not an important factor in the 
vitrification of ovarian specimens performed based on the protocol described in our experiments. It is generally accepted that small specimens yield better results (Ferreira et al., 2010). However, comparative data between small and large tissue fragments is scarce and studies on the topic refer to slow freezing, not vitrification.

The high variability observed in some of our results was probably due to random biological variability between individual animals. The study used ovaries collected in an abattoir, which means that we had no access to important data such as age or breed of the animals, and whether they were fertile females. This situation is very similar to what may happen in a human ovarian tissue banking service, where women of different ages and backgrounds may present diseases that may or not affect their fertility and the viability of their ovarian tissue specimens aftercryopreservation.

In conclusion, our data showed that vitrification of ovarian tissue fragments did not induce significant alterations in tissue antioxidant defense capacity. This is a reassuring finding, since the capability of a cell, tissue or whole organ to combat the oxidative stress induced by cryopreservation is a key factor for the survival and normal physiological function of the graft after rewarming and re-transplantation. We believe that the methodology described in this report can besafely extrapolated to human ovarian tissue banking for fertility preservationpurposes.

\section{ACKNOWLEDGEMENTS}

The authors would like to thank MSc Silvia Barbosa from the Morphological Sciences Department (ICBS/ UFRGS) for her invaluable aid in processing and storing the tissuespecimens.

\section{Conflicts of interest}

The authors have no conflict of interest to declare.

\section{Corresponding Author:}

Adriana Bos-Mikich

Department of Morphological Sciences, ICBS

Federal University of Rio Grande do Sul

Porto Alegre, RS, Brazil.

E-mail: adriana.bosmikich@gmail.com

\section{REFERENCES}

Abedelahi A, Salehnia M, Allameh AA, Davoodi D. Sodium selenite improves the in vitro follicular development by reducing the reactive oxygen species level and increasing the total antioxidant capacity and glutathione peroxide activity. Hum Reprod. 2010;25:977-85. PMID: 20139425 DOI: $10.1093 /$ humrep/deq002

Adler HI. The use of microbial membranes to achieve anaerobiosis. Crit Rev Biotechnol. 1990;10:119-27. PMID: 2202519 DOI: $10.3109 / 07388559009068263$

Almodin CG, Minguetti-Câmara VC, Meister H, Ferreira JO, Franco RL, Cavalcante AA, Radaelli MR, Bahls AS, Moron $A F$, Murta CG. Recovery of fertility after grafting of cryopreserved germinative tissue in female rabbits following radiotherapy. Hum Reprod. 2004;19:1287-93. PMID: 15117903 DOI: 10.1093/humrep/deh246
Aquino D, Danielli L, Rigon P, Lothhammer N, Frantz $\mathrm{N}$, Bos-Mikich A. Ovarian tissue vitrification: the use of a novel metal closed system for clinical grade cryopreservation. JBRA Assist Reprod. 2014;18:12-5. DOI: 10.5935/1518-0557.20140086

Bielanski A, Nadin-Davis S, Sapp T, Lutze-Wallace C. Viral contamination of embryos cryopreserved in liquid nitrogen. Cryobiology. 2000;40:110-6. PMID: 10788310 DOI: 10.1006/cryo.1999.2227

Browne RW, Armstrong D. Reduced glutathione and glutathione disulfide. Methods Mol Biol. 1998;108:347-52. PMID: 9921543 DOI: 10.1385/0-89603-472-0:347

Burd JF, Usategui-Gomez M. A colorimetric assay for serum lactate dehydrogenase. Clin Chim Acta. 1973;46:2237. PMID: 4725386 DOI: 10.1016/0009-8981(73)90174-5

Chan FK, Moriwaki K, De Rosa MJ. Detection of necrosis by release of lactate dehydrogenase activity. Methods Mol Biol. 2013;979:65-70. PMID: 23397389 DOI: 10.1007/978-1-62703-290-2_7

Chen SU, Chien CL, Wu MY, Chen TH, Lai SM, Lin CW, Yang YS. Novel direct cover vitrification for cryopreservation of ovarian tissues increases follicle viability and pregnancy capability in mice. Hum Reprod. 2006;21:2794-800. PMID: 16982660 DOI: 10.1093/humrep/del210

de Lamirande E, Gagnon C. Impact of reactive oxygen species on spermatozoa: a balancing act between beneficial and detrimental effects. Hum Reprod. 1995;10:15-21. PMID: 8592032 DOI: 10.1093/humrep/10.suppl_1.15

Dresch MTK, Rossato SB, Kappel VD, Biegelmeyer R, Hoff $M L$, Mayorga ML, Mayorga P, Zuanazzi JA, Henriques AT, Moreira JC. Optimization and validation of an alternative method to evaluate total reactive antioxidant potential. Anal Biochem. 2009;385:107-14. PMID: 19027710 DOI: 10.1016/j.ab.2008.10.036

Ellman GL. Tissue sulfhydryl groups. Arch Biochem Biophys. 1959;82:70-7. PMID: 13650640 DOI: 10.1016/0003-9861(59)90090-6

Fabbri R, Pasquinelli G, Keane D, Magnani V, Paradisi R, Venturoli S. Optimization of protocols for human ovarian tissue cryopreservation with sucrose, 1,2-propanediol and human serum. Reprod BioMed Online. 2010;21:819-28. PMID: 21050819 DOI: 10.1016/j.rbmo.2010.07.008

Ferreira M, Bos-Mikich A, Frantz N, Rodrigues JL, Brunetto $A L$, Schwarstmann G. The Effects of Sample Size on the Outcome of Ovarian Tissue Cryopreservation. Reprod Domest Anim. 2010;45:99-102. PMID: 18992115 DOI: 10.1111/j.1439-0531.2008.01261.x

Haidari K, Salehnia M, Rezazadeh Valojerdi M. The effect of leukemia inhibitory factor and coculture on the in vitro maturation and ultrastructure of vitrified and nonvitrified isolated mouse preantral follicles. Fertil Steril. 2008;90:2389-97. PMID: 18462725 DOI: 10.1016/j.fertnstert.2007.10.052 
Hatami S, Zavareh S, Salehnia M, Lashkarbolouki T, Karimi I. Comparison of oxidative status of mouse pre-antral follicles derived from vitrified whole ovarian tissue and vitrified pre-antral follicles in the presence of alpha lipoic acid. J Obstet Gynaecol Res. 2014;40:1680-8. PMID: 24888934 DOI: $10.1111 /$ jog.12394

Isachenko V, Lapidus I, Isachenko $E$, Krivokharchenko A, Kreienberg R, Woriedh M, Bader M, Weiss JM. Human ovarian tissue vitrification versus conventional freezing: morphological, endocrinological, and molecular biological evaluation. Reproduction. 2009;138:319-27. PMID: 19439559 DOI: $10.1530 /$ REP-09-0039

Keros V, Xella S, Hultenby K, Pettersson K, Sheikhi M, Hreinsson J, Hovatta $O$. Vitrification versus controlled-rate freezing in cryopreservation of human ovarian tissue. Hum Reprod. 2009;24:1670-83. PMID: 19359339 DOI: 10.1093/humrep/dep079

Korzeniewski C, Callewaert DM. An enzyme-release assay for natural cytotoxicity. J Immunol Methods. 1983;64:31320. PMID: 6199426 DOI: 10.1016/0022-1759(83)90438-6

Lissi E, Salim-Hanna M, Pascual C, del Castillo MD. Evaluation of total antioxidant potential (TRAP) and total antioxidant reactivity from luminol-enhanced chemiluminescence measurements. Free Radic Biol Med. 1995;18:153-8. PMID: 7744297 DOI: 10.1016/0891-5849(94)00117-3

Marques L, Bos-Mikich A, Godoy LC, Silva LA, Maschio D, Zhang T, Streit DP Jr. Viability of zebrafish (Danio rerio) ovarian follicles after vitrification in a metal container. Cryobiology. 2015;71:367-73. PMID: 26408854 DOI: 10.1016/j.cryobiol.2015.09.004

Mazoochi T, Salehnia M, Pourbeiranvand S, Forouzandeh M, Mowla SJ, Hajizadeh E. Analysis of apoptosis and expression of genes related to apoptosis in cultures of follicles derived from vitrified and non-vitrified ovaries. Mol Hum Reprod. 2009;15:155-64. PMID: 19155222 DOI: 10.1093/molehr/gap002

Mazur P, Katkov II, Katkova N, Critser JK. The enhancement of the ability of mouse sperm to survive freezing and thawing by the use of high concentrations of glycerol and the presence of an Escherichia coli membrane preparation (Oxyrase) to lower the oxygen concentration. Cryobiology. 2000;40:187-209. PMID: 10860619 DOI: $10.1006 /$ cryo.2000.2238

Migishima $F$, Suzuki-Migishima $R$, Song SY, Kuramochi T, Azuma S, Nishijima M, Yokoyama M. Successful cryopreservation of mouse ovaries by vitrification. Biol Reprod. 2003;68:881-7. PMID: 12604638 DOI: 10.1095/biolreprod.102.007948

Pomeroy KO, Harris S, Conaghan J, Papadakis M, Centola G, Basuray R, Battaglia D. Storage of cryopreserved reproductive tissues: evidence that cross-contamination of infectious agents is a negligible risk. Fertil Steril. 2010;94:11818. PMID: 19481743 DOI: $10.1016 /$ j.fertnstert.2009.04.031
Preissler T, Bristot IJ, Costa BM, Fernandes EK, Rieger E, Bortoluzzi VT, de Franceschi ID, Dutra-Filho CS, Moreira JC, Wannmacher CM. Phenylalanine induces oxidative stress and decreases the viability of rat astrocytes: possible relevance for the pathophysiology of neurodegeneration in phenylketonuria. Metab Brain Dis. 2016;31:529-37. PMID 26573865 DOI: $10.1007 /$ s11011-015-9763-0

Ruder EH, Hartman TJ, Blumberg J, Goldman MB. Oxidative stress and antioxidants: exposure and impact on female fertility. Hum Reprod Update. 2008;14:345-57. PMID: 18535004 DOI: 10.1093/humupd/dmn011

Sheikhi M, Hultenby K, Niklasson B, Lundqvist M, Hovatta $O$. Clinical grade vitrification of human ovarian tissue: an ultrastructural analysis of follicles and stroma in vitrified tissue. Hum Reprod. 2011;26:594-603. PMID: 21217141 DOI: $10.1093 /$ humrep/deq357

Shkolnik K, Tadmor A, Ben-Dor S, Nevo N, Galiani D, Dekel N. Reactive oxygen species are indispensable in ovulation. Proc Natl Acad Sci U S A. 2011;108:1462-7. PMID: 21220312 DOI: $10.1073 /$ pnas. 1017213108

Silva E, Greene AF, Strauss K, Herrick JR, Schoolcraft WB, Krisher RL. Antioxidant supplementation during in vitro culture improves mitochondrial function and development of embryos from aged female mice. Reprod Fertil Dev. 2015;27:975-83. PMID: 25739837 DOI: 10.1071/RD14474

Smith SM, Wunder MB, Norris DA, Shellman YG. A simple protocol for using a LDH-based cytotoxicity assay to assess the effects of death and growth inhibition at the same time. PLoS One. 2011;6:e26908. PMID: 22125603 DOI: $10.1371 /$ journal.pone.0026908

Sugimoto M, Maeda S, Manabe N, Miyamoto H. Development of infantile rat ovaries autotransplanted after cryopreservation by vitrification. Theriogenology. 2000;53:1093-103. PMID: 10798487 DOI: $10.1016 /$ S0093-691X(00)00255-7

Tokieda Y, Ishiwata I, Segino M, Ishikawa H, Sato K. Establishment of a novel method for cryopreservation and thawing of the mouse ovary. Hum Cell. 2002;15:230-7. PMID: 12889859 DOI: $10.1111 /$ j.1749-0774.2002.tb00120.x

Vu HV, Lee S, Acosta TJ, Yoshioka S, Abe H, Okuda K. Roles of prostaglandin F2alpha and hydrogen peroxide in the regulation of Copper/Zinc superoxide dismutase in bovine corpus luteum and luteal endothelial cells. Reprod Biol Endocrinol. 2012;10:87. PMID: 23101731 DOI: 10.1186/1477-7827-10-87

Xiao J, Liu Y, Li Z, Zhou Y, Lin H, Wu X, Chen M, Xiao W. Effects of the insemination of hydrogen peroxide-treated epididymal mouse spermatozoa on $\mathrm{YH} 2 \mathrm{AX}$ repair and embryo development. PLoS One. 2012;7:e38742. PMID: 22745678 DOI: $10.1371 /$ journal.pone.0038742

Zor T, Selinger Z. Linearization of the Bradford protein assay increases its sensitivity: theoretical and experimental studies. Anal Biochem. 1996;236:302-8. PMID: 8660509 DOI: $10.1006 /$ abio.1996.0171 